\title{
Comparison of analgesic efficacy of bupivacaine, bupivacaine with dexmedetomidine, and bupivacaine with fentanyl in local perianal infiltration technique in perianal surgeries: $A$ prospective, randomized controlled study
}

\author{
V Haribabu ${ }^{1}, \mathrm{~K}$ Gopalakrishnan ${ }^{2}$, M Suresh Rajkumar ${ }^{3}$, V Ezhil Rajan ${ }^{4}$, R Chandrasekar $^{5}$ \\ $\left\{{ }^{1}\right.$ Associate Professor, ${ }^{2}$ Assistant Professor, ${ }^{3}$ Professor, ${ }^{4}$ Professor, Department of Anaesthesiology $\}\left\{{ }^{5}\right.$ Professor, Department of Surgery\} \\ Aarupadai Veedu Medical College \& Hospital, Puducherry, INDIA. \\ Email: drkgpal73@gmail.com
}

Abstract Background: Numerous methods have been proposed to alleviate pain after perianal surgeries but the role of addition of Dexmedetomidine or fentanyl to bupivacaine as local infiltration in surgical wound for post-operative analgesic effect is less explored. Hence a study was conducted to compare the efficacy of wound infiltration with bupivacaine, bupivacaine with fentanyl and bupivacaine with Dexmedetomidine for post-operative analgesia following perianal surgeries. Methods: 75 patients with ASA physical status of I and II scheduled for perianal surgeries were recruited for the study. The patients were randomly assigned into 3 groups namely DM, F and C. Group DM received perianal wound infiltration with $0.5 \%$ bupivacaine $15 \mathrm{ml}$ which included Dexmedetomidine $1.5 \mu \mathrm{g} / \mathrm{kg}$, Group F received perianal wound infiltration with $0.5 \%$ bupivacaine 15 $\mathrm{ml}$ which included Fentanyl $2 \mu \mathrm{g} / \mathrm{ml}$ and Group C received perianal wound infiltration with $0.5 \%$ bupivacaine $15 \mathrm{ml}$ which included $1 \mathrm{ml}$ saline. Post-operative quality of analgesia was assessed by VAS (0-10) for $24 \mathrm{~h}$ and rescue analgesic was administered when VAS $>4$. Pain score at the time of defecation was also noted. Total dose of analgesic needed in 24 hours and side effects were noted. Results: Group DM had significantly longer duration of postoperative analgesia when compared with Group F and group C. Group F had prolonged postoperative analgesia when compared to Group C. The pain score at first defecation was significantly lower in Group DM when compared to both Group F and Group C. None of the patients developed skin rash, respiratory depression, hypotension, hypoxemia, and there were no significant tachycardia or bradycardia. Conclusions: Perianal wound infiltration with Dexmedetomidine-bupivacaine mixture provides prolonged analgesia, and decreases the total analgesic consumption in patients undergoing perianal surgeries.

Key Words: Analgesia, Dexmedetomidine, fentanyl, perianal surgeries, perianal wound infiltration.

*Address for Correspondence:

Dr K. Gopalakrishnan, Assistant Professor, Department of Anesthesiology, Aarupadai Veedu Medical College \& Hospital, Puducherry, INDIA.

Email: $\underline{\text { drkgpal73@gmail.com }}$

Received Date: 11/04/2020 Revised Date: 14/05/2020 Accepted Date: 09/06/2020

DOI: https://doi.org/10.26611/10151513

This work is licensed under a Creative Commons Attribution-NonCommercial 4.0 International License. $(\boldsymbol{C c})$ EY-NC

\begin{tabular}{|l|l|}
\hline \multicolumn{2}{|c|}{ Access this article online } \\
\hline Quick Response Code: & Website: \\
& www.medpulse.in \\
\cline { 2 - 2 } & \\
\hline
\end{tabular}

\section{INTRODUCTION}

Ano-rectal disorders affect about $5 \%$ of adult population ${ }^{1}$. Haemorrhoids, fistula-in-ano and anal fissure comprise most of them. Surgical treatment for these assures the patient a better quality of life ${ }^{2}$. Ano-rectal surgeries have conventionally been performed under general anesthesia (GA) and spinal anesthesia (SA) ${ }^{1}$. Postoperative pain is said to be most severe in anorectal surgery and thus, the choice of anesthetic methods in this procedure is crucial to reduce the postoperative pain as well as postoperative complications ${ }^{3}$. Spinal anesthesia for anorectal surgery is a 
popular and commonly used method characterized by rapid onset and offset, easy mobilization and short hospital stay ${ }^{4}$. No matter how skillfully conducted or successful the result, almost all surgical procedures produce tissue trauma and pain. Immediate pain is very severe in anorectal surgery and difficult to control with only intravenous analgesics ${ }^{3}$. Conventionally, nonsteroidal antiinflammatory drugs (NSAIDs) and opiates have often been used to control pain, but their use is confined to a short period of time and is associated with frequent side effects, including gastrointestinal problems, renal dysfunction, nausea and vomiting, increased urinary retention, and reduced bowel mobility ${ }^{5}$. Also a variety of methods for reducing pain after hemorrhoidectomy and other perianal surgeries have been investigated, including pudendal nerve block, perianal infiltration of local anesthetics or botulinum toxin, and application of topical preparation such as metronidazole, glyceryl nitrate, and calcium channel blocker ${ }^{5}$. Incisional infiltration with local anesthetics has been documented to improve postoperative pain control after inguinal hernia repair or laparoscopic cholecystectomy ${ }^{15}$. Infiltration with local anesthetics may also participate in providing adequate pain control after anorectal surgeries ${ }^{7}$. Few studies have investigated the effects of addition of pharmacological agents like dexmedetomidine ${ }^{10,11,18}$, fentany $1^{14}$, etc to the incisional wound infiltration in various surgeries ${ }^{12}$. Few studies have investigated the effects of addition of ketamine ${ }^{6}$, dexmedetomidine $^{5}$ etc to perianal local anaesthetic infiltration in perianal surgeries. However, there is no sufficient clinical data regarding the effects of addition of dexmedetomidine or fentanyl to the local infiltration on postoperative pain. Hence a study was conducted to compare the efficacy of addition of dexmedetomidine and fentanyl in prolonging the postoperative analgesia when added to local anaesthetic solution in wound infiltration technique in patients undergoing perianal surgeries.

\section{MATERIALS AND METHODS}

Subsequent to receiving institutional ethical committee approval, registrations at clinical trials registry CTRI/2018/12/016807 (Registered on: 31/12/2018), and after obtaining written informed consent, American Society of Anesthesiologists (ASA) I-II patients of age 1850 years of both gender with normal range of BMI undergoing perianal surgeries like fissure in ano, fistula in ano and haemorrhoidectomy in Aarupadai Veedu Medical College and Hospital, Puducherry from December 2018 to November 2019 were selected for the study. A prospective, randomised, placebo controlled, parallel group, double blinded, clinical trial study was conducted. Randomisation was computer generated. ASA III and above, obese, underweight subjects (extremes of BMI), pregnant women, patients with bleeding and clotting disorders, allergic to local anesthetic agents, inadequate spinal blockade supplemented by other drugs and complicated surgeries were excluded from the study. To assess pain, visual analogue scale (VAS) $(0-10 \mathrm{~cm})$ was utilized and instructions were given for all patients in the context of pain assessment from 0 to 10 , with 0 indicating no pain and 10 indicating the worst pain imaginable during pre anaesthetic visit in the evening prior to surgery. Seventy five patients were randomly assigned into 3 groups. None of the patients received premedication. In all the three groups, surgery was done under spinal analgesia. The subarachnoid block was performed using 26G Quincke s type pointed spinal needle in all patients in sitting position at the level of $\mathrm{L}_{3}-\mathrm{L}_{4}$ space with $2.0 \mathrm{ml}$ of $0.5 \%$ bupivacaine heavy. Patients were monitored with electrocardiogram, noninvasive arterial blood pressure and pulse oximetry in the operating room. Perianal wound infiltration was performed at the end of the procedure.

* Group DM received wound infiltration with 0.5\% bupivacaine $15 \mathrm{ml}$ which included dexmedetomidine 1.5 $\mu \mathrm{g} / \mathrm{kg}$.

* Group F received wound infiltration with $0.5 \%$ bupivacaine $15 \mathrm{ml}$ which included Fentanyl $2 \mu \mathrm{g} / \mathrm{ml}$

* Group C received wound infiltration with $0.5 \%$ bupivacaine $15 \mathrm{ml}$ which included $1 \mathrm{ml}$ saline.

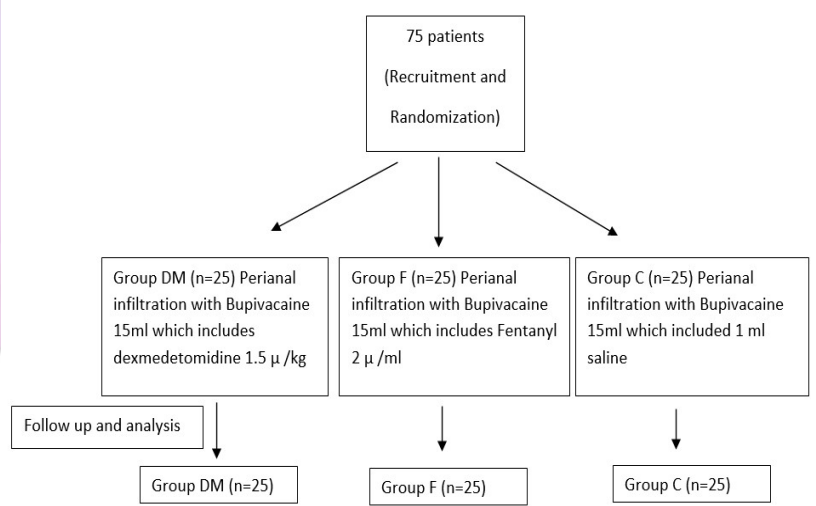

None of the patients in either group had any complications intraoperatively. Patient was then transferred to the recovery room, and baseline vital parameters were recorded. The outcome assessor and the patient were blinded. Duration of surgery and duration of spinal blockade were recorded. Vital parameters MAP (mean arterial pressure), Pulse rate and Respiratory rate were observed every 30 min till first 2 hrs, at 6, 12, 18 and 24 $\mathrm{hr}$. Hypotension was defined as a decrease in systolic arterial blood pressure $>20 \%$ of baseline and was treated with intravenous (IV) 5---10 mg bolus doses of ephedrine. Bradycardia was defined as heart rate $<60$ beat per minute and were treated with $0.01 \mathrm{mg} / \mathrm{kg}$ bolus dose of atropine. 
Respiratory depression was defined as respirate rate $<10$ and alert was given to anaesthesiologist. Pain intensity was measured on a visual analog scale (VAS) graded from 0 (no pain) to $10 \mathrm{~cm}$ (the maximum pain imaginable). Pain assessment was performed at rest and movement every 2 hrs from the end of surgery till $24 \mathrm{hrs}$ and at the time of the first defecation. Any patient complaining of pain or reporting VAS $>4$ at any time was administered tramadol $50 \mathrm{mg}$ IV slowly over $2-3 \mathrm{~min}$. If pain was not relieved after $30 \mathrm{~min}$ and patients still complained of pain, additional doses of tramadol $50 \mathrm{mg}$ IV were given, and this dose could be repeated every $30 \mathrm{~min}$ up to a total dose of $250 \mathrm{mg}$ in 6 hours and maximum of $400 \mathrm{mg}$ of tramadol over $24 \mathrm{~h}$. The time of first rescue analgesic administration and total analgesic requirement in the 24 hours were noted. Postoperative side effects like sedation, nausea, vomiting, headache and pruritus were recorded.
The sedation score on a 6-point Ramsey sedation scale was used.

\begin{tabular}{|c|c|}
\hline 1 & Patient awake, anxious, agitated or restless \\
\hline 2 & Patient awake, cooperative, oriented and tranquil \\
\hline 3 & Patient Drowsy, with response to commands \\
\hline 4 & $\begin{array}{c}\text { Patient asleep, brisk response to glabella tap or loud } \\
\text { auditory stimulus }\end{array}$ \\
\hline 5 & Patient asleep, sluggish response to stimulus \\
\hline 6 & $\begin{array}{c}\text { Patient has no response to firm nail-bed pressure or other } \\
\text { noxious stimuli }\end{array}$ \\
\hline
\end{tabular}

When the patient had a sedation score of 4and above, supplement oxygen $6 \mathrm{~L} / \mathrm{min}$ was administered and alert was given to the anaesthesiologist. Inj. Ondansetron $4 \mathrm{mg}$ was given slow IV for nausea and vomiting.

Statistical Analysis:

Collected data were analyzed using appropriate descriptive and inferential statistics using SPSS 15.0-Software. Normally distributed interval and ratio data were analyzed using ANOVA test. Ordinal data were analyzed using Kruskal Wallis test. Nominal data were analyzed using Chi square or Fischer Exact. Data were analyzed for statistical significance of $p$ value $<0.05$. If the difference was found to be significant, further between the groups analyses were carried out.

\section{RESULTS}

No significant difference was observed between the groups with respect to gender, age, height, weight, BMI, ASA physical status and distribution of surgical diagnoses. The groups were comparable in regards to duration of surgery and duration of spinal analgesia. (Table 1).

Table 1: Patients characteristics and clinical data

\begin{tabular}{ccccc}
\hline Variable & $\begin{array}{c}\text { Group DM } \\
(\mathrm{n}=\mathbf{2 5})\end{array}$ & Group F $(\mathrm{n}=\mathbf{2 5})$ & $\begin{array}{c}\text { Group C } \\
(\mathrm{n}=\mathbf{2 5})\end{array}$ & P value \\
\hline ASA I/II (n) & $22 / 3$ & $21 / 4$ & $22 / 3$ & $>0.05$ \\
Gender (Male/Female) & $22 / 3$ & $22 / 3$ & $23 / 2$ & $>0.05$ \\
Surgery-Fissure/Haemorrhoids/Fistula & $12 / 7 / 6$ & $11 / 7 / 7$ & $11 / 6 / 8$ & $>0.05$ \\
Age ( years) & $40.8 \pm 8.6$ & $41.3 \pm 6.5$ & $39.5 \pm 9.3$ & $>0.05$ \\
Weight $(\mathrm{kg})$ & $72.2 \pm 5.3$ & $70.6 \pm 6.1$ & $69.4 \pm 5.0$ & $>0.05$ \\
Height (m) & $1.63 \pm 0.06$ & $1.62 \pm 0.06$ & $1.63 \pm 0.07$ & $>0.05$ \\
BMI (m ( $^{-1}$ ) & $27.13 \pm 1.75$ & $26.86 \pm 1.66$ & $26.19 \pm 1.68$ & $>0.05$ \\
Duration of surgery (min) & $23.4 \pm 8.6$ & $24 \pm 8.9$ & $23.6 \pm 8.7$ & $>0.05$ \\
Duration of spinal analgesia (min) & $134.4 \pm 10.44$ & $133.2 \pm 11.45$ & $132.8 \pm 12.08$ & $>0.05$ \\
\hline
\end{tabular}

Ratio or interval data are expressed as mean SD and ASA I or II and Gender are expressed as numbers.

Table 2: VAS scores observed in both groups at rest and at movement (median and range)

\begin{tabular}{|c|c|c|c|c|c|c|c|c|}
\hline \multirow[b]{2}{*}{ Time } & \multicolumn{4}{|c|}{ VAS score at rest } & \multicolumn{4}{|c|}{ VAS score on movement } \\
\hline & $\begin{array}{c}\text { Group DM } \\
(n=25)\end{array}$ & $\begin{array}{l}\text { Group F } \\
(n=25)\end{array}$ & $\begin{array}{c}\text { Group C } \\
(n=25)\end{array}$ & $\begin{array}{c}P \\
\text { value }\end{array}$ & $\begin{array}{c}\text { Group DM } \\
(n=25)\end{array}$ & $\begin{array}{l}\text { Group F } \\
(n=25)\end{array}$ & $\begin{array}{c}\text { Group C } \\
(n=25)\end{array}$ & $P$ value \\
\hline & $\begin{array}{c}\text { Median } \\
\text { (min-max) }\end{array}$ & Median (min-max) & $\begin{array}{c}\text { Median } \\
(\text { min-max) }\end{array}$ & & $\begin{array}{c}\text { Median } \\
(\min -\max )\end{array}$ & Median (min-max) & $\begin{array}{c}\text { Median } \\
\text { (min-max) }\end{array}$ & \\
\hline $2 \mathrm{hr}$ & $0(0-0)$ & $0(0-0)$ & $0(0-0)$ & & $0(0-0)$ & $0(0-0)$ & $0(0-0)$ & \\
\hline $4 \mathrm{hr}$ & $0(0-0)^{*}$ & $0(0-1) \#$ & $1(0-5)$ & $<0.5$ & $0(0-0)^{*}$ & $0(0-1)$ & $1(0-6)$ & $<0.5$ \\
\hline $6 \mathrm{hr}$ & $0(0-0)^{*}$ & $2(2-5)$ & $2(2-5)$ & $<0.5$ & $0(0-0)^{*}$ & $3(2-5)$ & $2(2-5)$ & $<0.5$ \\
\hline $8 \mathrm{hr}$ & $0(0-2)^{*}$ & $5(0-5)$ & $5(0-5)$ & $<0.5$ & $0(0-3)^{*}$ & $5(0-5)$ & $5(0-6)$ & $<0.5$ \\
\hline $10 \mathrm{hr}$ & $1(0-5)$ & $0(0-2)$ & $1(0-2)$ & $>0.5$ & $2(2-6)^{*}$ & $1(0-3)$ & $1(0-3)$ & $<.5$ \\
\hline $12 \mathrm{hr}$ & $2(2-5)$ & $2(2-5)$ & $2(1-5)$ & $>0.5$ & $3(2-6)$ & $2(1-5)$ & $3(2-6)$ & $>0.5$ \\
\hline $14 \mathrm{hr}$ & $4(2-5)$ & $4(2-4)$ & $2(1-4)$ & $<0.5$ & $5(2-6)$ & $4(2-4)$ & $4(2-6)$ & $>0.5$ \\
\hline
\end{tabular}




\begin{tabular}{|c|c|c|c|c|c|c|c|c|}
\hline $16 \mathrm{hr}$ & $2(0-4)$ & $2(1-3)$ & $2(1-6)$ & $<0.5$ & $2(0-6)$ & $2(1-3)$ & $3(2-3)$ & $>0.5$ \\
\hline $18 \mathrm{hr}$ & $1(0-5)$ & $2(2-4)$ & $3(0-5)$ & $>0.5$ & $2(0-6)$ & $3(2-5)$ & $4(1-5)$ & $>0.5$ \\
\hline $20 \mathrm{hr}$ & $2(1-5)$ & $5(0-5)$ & $1(0-5)$ & $>0.5$ & $2(1-6)$ & $6(0-6)$ & $2(0-6)$ & $>0.5$ \\
\hline $22 \mathrm{hr}$ & $5(2-5)$ & $2(0-3)$ & $2(2-4)$ & $<0.5$ & $5(2-6)$ & $2(2-3)$ & $3(2-4)$ & $<0.5$ \\
\hline $24 \mathrm{hr}$ & $2(0-4)$ & $4(2-5)$ & $5(2-5)$ & $<0.5$ & $2(2-5)$ & $5(4-6)$ & $6(5-6)$ & $<0.5$ \\
\hline
\end{tabular}

*DM significant to both $\mathrm{F}$ and $\mathrm{C}$, \#F significant to $\mathrm{C}$

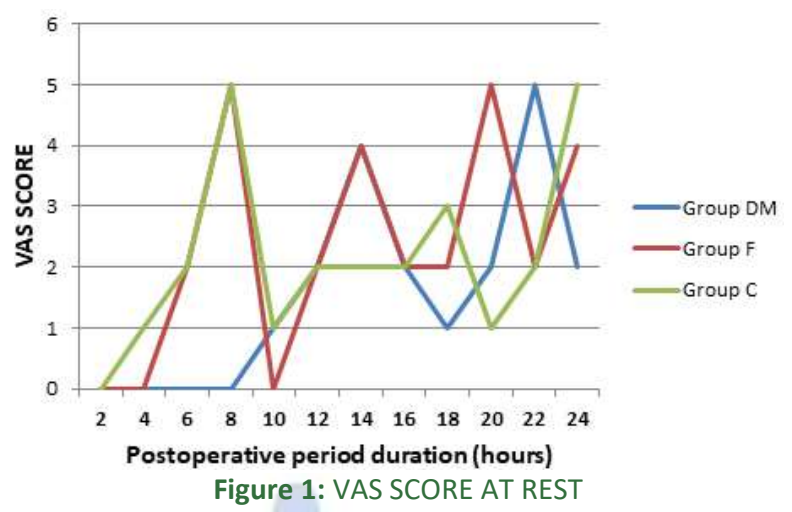

Median VAS score at rest and on movement of all the three groups were given in the table 2. Fig 1 shows the median value of all groups over $24 \mathrm{hrs}$. DM group had lower VAS scores than other groups till an average of 8 hours and was found to be statistically significant $(\mathrm{p}<0.01)$. There were no statistically significant differences in VAS scores among the groups at 10 and 12 hours intervals. But the median was lower and variation in range was narrow in Group DM. After 12 hours, the VAS scores did not have consistent difference.

Table 3: First analgesic request and total consumption of Tramadol

\begin{tabular}{|c|c|c|c|c|}
\hline Variable & $\begin{array}{c}\text { Group DM } \\
(\mathrm{n}=25)\end{array}$ & $\begin{array}{l}\text { Group F } \\
(n=25)\end{array}$ & $\begin{array}{c}\text { Group C } \\
(n=25)\end{array}$ & 'p' value \\
\hline $\begin{array}{l}\text { Time for First analgesic request } \\
\qquad(\mathrm{min})\end{array}$ & $\begin{array}{c}921.6 \pm 260.89 \\
(*)\end{array}$ & $422.4 \pm 61.19$ (\#) & $336 \pm 84.85$ & $<0.001$ \\
\hline $\begin{array}{l}\text { Total Tramadol consumption in } 24 \\
\text { hrs (mg) }\end{array}$ & $88 \pm 41.5\left(^{*}\right)$ & $182 \pm 24.5$ (\#) & $208 \pm 18.7$ & $<0.001$ \\
\hline \multicolumn{5}{|c|}{$\begin{array}{l}\text { Data are expressed as mean } \pm S D \\
\text { ' } p \text { ' value }<0.05 \text { is considered a significant }\end{array}$} \\
\hline
\end{tabular}

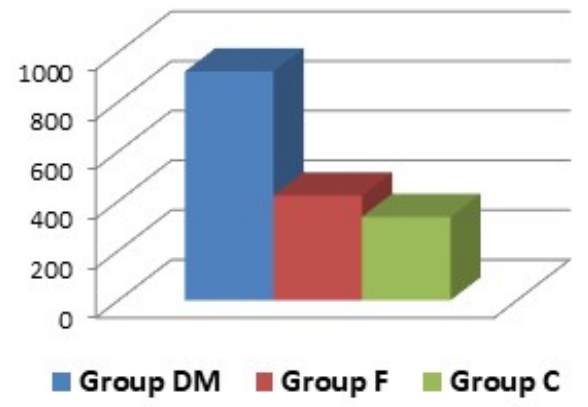

Figure 2: First Analgesic requirement ( $\mathrm{min})$

The need for rescue analgesic for the first time was at 921.6 260.89 minutes in Group DM, at $422.4 \quad 61.19 \mathrm{~min}$ in F group and at 33684.85 minutes in Group C (Table 3, Fig 2).Thus, the need for the first dose of rescue analgesia was earlier in Group C as compared to Groups DM and F and the difference was statistically significant $(\mathrm{p}<0.05)$. Group DM had longer duration of postoperative analgesia when compared with Group F ( $p<0.05)$. 


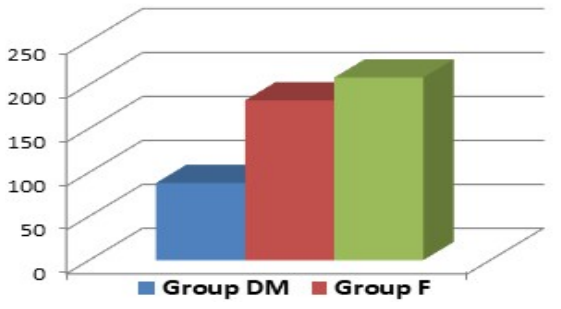

Figure 3: Total Tramadol consumption (mg)

The 24 hours analgesic requirement in Group DM was lower $88 \quad 41.5 \mathrm{mg}$ when compared with Group F $182 \quad 24.5 \mathrm{mg}$ and Group C with $20818.7 \mathrm{mg}$ and the difference was statistically significant $(\mathrm{p}<0.05)$ (Table 3, Fig 3). Group F had lower analgesic requirement than Group C $(\mathrm{p}<0.05)$.

Table 4: Pain score at First defecation

\begin{tabular}{cccc}
\hline \multicolumn{4}{c}{$\begin{array}{c}\text { First Defecation VAS score } \\
\text { Median (min-max) }\end{array}$} \\
\hline $\begin{array}{c}\text { Group DM } \\
(n=25)\end{array}$ & $\begin{array}{c}\text { Group F } \\
(n=25)\end{array}$ & $\begin{array}{c}\text { Group C } \\
(n-25)\end{array}$ & P value \\
$2(2-3) *$ & $3(2-4)$ & $3(2-4)$ & $<0.001$ \\
\hline *DM significant to both F and C, \#F significant to C
\end{tabular}

The Median pain score at first defecation score was lower (2) in Group DM when compared to both Group F and Group C median scores, both had $3(\mathrm{p}<0.05)$. There was no significant difference in the VAS score at first defecation between the Group F and Group C ( $>>0.05)$ (Table 4). There was no statistically significant difference between the groups in MAP (Mean Arterial Pressure), Pulse rate and Respiratory rate in all measurement intervals $(\mathrm{p}>0.05)$.

Table 5: Adverse event rates

\begin{tabular}{ccccc}
\hline Adverse event & $\begin{array}{c}\text { Group DM } \\
\mathbf{n}=\mathbf{2 5}\end{array}$ & $\begin{array}{c}\text { Group } \mathbf{F} \mathbf{n}= \\
\mathbf{2 5}\end{array}$ & $\begin{array}{c}\text { Group C } \mathbf{n}= \\
\mathbf{2 5}\end{array}$ & P value \\
\hline Hypotension & $\mathrm{Nil}$ & $\mathrm{Nil}$ & $\mathrm{Nil}$ & \\
Hypertension & $\mathrm{Nil}$ & $\mathrm{Nil}$ & $\mathrm{Nil}$ & \\
Tachycardia & $\mathrm{Nil}$ & $\mathrm{Nil}$ & $\mathrm{Nil}$ & \\
Bradycardia & $\mathrm{Nil}$ & $\mathrm{Nil}$ & $\mathrm{Nil}$ & \\
Postoperative sedation & $\mathrm{Nil}$ & $\mathrm{Nil}$ & $\mathrm{Nil}$ & \\
Nausea vomiting & 3 & 7 & 9 & $>0.05$ \\
Pruritis & $\mathrm{Nil}$ & $\mathrm{Nil}$ & $\mathrm{Nil}$ & \\
\hline
\end{tabular}

None of the patients developed skin rash, respiratory depression, postoperative sedation, hypotension, hypoxemia, and there were no significant tachycardia or bradycardia. Group DM had fewer incidences of nausea vomiting than Group F and Group C, but this difference was not statistically significant ( $>0.05)$. There was no statistical significant difference in the median sedation score among the groups $(p>0.05)$ though Group DM had higher median sedation score (3) in the first 12 hours when compared to median sedation scores of Group F (2) and Group C (2). Within Group DM, patients who underwent surgery for Fissure in ano had longer postoperative analgesia $1170 \quad 103.9$ minutes when compared to the patients who underwent Fistulectomy $700 \quad 117.9$ minutes and Haemorrhoidectomy 685.3 58.6 minutes (Table 6). This difference was statistically significant $(\mathrm{p}<0.05)$ and there was no statistically significant difference between patients who underwent Fistulectomy and Haemorrhoidectomy surgeries.

\begin{tabular}{|c|c|c|c|c|c|}
\hline & $\begin{array}{l}\text { Fissure in ano } \\
\quad(n=12)\end{array}$ & $\begin{array}{l}\text { Hamaerrhoidectomy } \\
(n=7)\end{array}$ & Fistula in ano $(n=6)$ & & $P$ value \\
\hline $\begin{array}{c}\text { First rescue } \\
\text { Analgesic time (min) }\end{array}$ & $1170 \pm 103.9\left(^{*}\right)$ & $685.3 \pm 58.6$ & $700 \pm 117.9$ & 74.99 & $<0.001$ \\
\hline
\end{tabular}

* Patients who underwent Fissure in ano surgery had significantly longer duration than patients who underwent both other 2 surgeries. 


\section{DISCUSSION}

Perianal surgeries form significant part of surgical practice. Spinal analgesia (SA) and General anaesthesia (GA) techniques are the commonly administered anaesthetic techniques for such cases. However, spinal analgesia technique seems to be simple and relatively inexpensive ${ }^{8}$. Management of post surgical pain is an important aspect of perioperative anaesthetic care, since acute postsurgical pain affects surgical outcomes. The post operative pain is a major cause of prolonged stay and patient dissatisfaction, necessitating the need for the anesthesiologist to provide a good postoperative analgesia that fastens patient recovery and also makes mobilization much easier ${ }^{9}$. Wound infiltration at the end of surgery with local anaesthetic agent bupivacine for perianal surgeries is commonly followed by many and is simple to perform. To the best of our knowledge, there are only few articles on effects of addition of pharmacological agents like dexmedetomidine and fentanyl to the local solution during such postoperative wound infiltration. Dexmedetomidine, an alpha-2 adrenoceptor agonist provides analgesia and sedation when administered through intravenous, epidural and intrathecal route without respiratory depression but however its synergistic action with local anesthetic agent when administered by local infiltration is not well studied ${ }^{10}$ Our current study showed significant good analgesic effect of dexmedetomidine when combined with bupivacaine in wound infiltration in perianal surgeries. Median VAS score and the range at rest and on movement of all the three groups were given in the table 2. Group DM had lower VAS scores than other groups till an average of 8 hours and was found to be statistically significant $(p<0.01)$. Thereafter, there were no statistically significant differences in VAS scores among the groups at 10 and 12 hours intervals as Group F and Group C had already received tramadol rescue analgesia by that time. But the median was lower and variation in range was narrow in Group DM. After 12 hours, the VAS scores significance varied as each group received Tramadol injection at different point of time. Study by Abdelnaim et al.. ${ }^{11}$ demonstrated that addition of dexmedetomidine with local anesthetics to wound infiltration reduces postoperative pain and also reduces the analgesic requirement which was explained by different mechanisms. The probable mechanisms are inhibition of pain conduction in C-fibers, decreasing the production of inflammatory cytokines, vasoconstrictive effect of alpha 2 agonists on vascular smooth muscle prolongs the time of analgesia. ${ }^{12}$ Our study was similar to study by Neha Kadyan et al. ${ }^{12}$ who demonstrated that the addition of dexmedetomidine in wound infiltration with bupivacaine after abdominal hysterectomy showed reduced post-operative pain scores when compared with the control group. Another study by
Vinson-Bonnet et al. ${ }^{7}$. also reported that perianal infiltration using bupivacaine with dexmedetomidine improved immediate postoperative pain control after hemorrhoidectomy, up to $6 \mathrm{~h}$.

Results of our study well correlated with the study of Kang et al. ${ }^{13}$ where he observed that there was significant reduction in pain scores and fentanyl consumption in group of patients with dexmedetomidine added to ropivacaine wound infiltration than patients in group of patients with ropivacaine wound infiltration alone. Group $\mathrm{F}$ had lower scores than control group at 4 hours interval and it was found to be statistically significant. There was no statistically significant difference in VAS scores between group $\mathrm{F}$ and group $\mathrm{C}$ after 4 hours. A study by Chander et al. ${ }^{14}$ reported that the mean duration of analgesia was higher in the fentanyl bupivacaine group compared to the bupivacaine alone group. This observation supports the peripheral analgesic effect of opioids. But however this combination of opioid with bupivaciane is not as effective as combination of dexmedetomidine with bupivacaine. First analgesic requirement time was longer (921.6 260.89 $\mathrm{min}$ ) in DM group than Group F group ( $422.4 \quad 61.19 \mathrm{~min}$ ) and Control group (336 $84.85 \mathrm{~min})$ (Table 3). Between Fentanyl and control groups, Fentanyl group had longer analgesia than Control group $(\mathrm{p}<0.05)$. A study by Selvaraj et al. ${ }^{15}$ showed that addition of dexmedetomidine to bupivacaine as local wound infiltration in port site during laparoscopic cholecystectomy prolonged the duration of analgesia, thus delayed the need for rescue analgesics in the first 8 hours of the postoperative period. Chander at al. demonstrated that the requirement of analgesic was as early as 2 hours in the control group infiltrated with bupivacaine alone and the difference was as marked as $40 \%$ as compared to $3 \%$ in group where fentanyl was added to bupivacaine. In our study, total tramadol requirement in 24 hour was significantly lower in DM group ( $88 \quad 41.5 \mathrm{mg}$ ) as compared to fentanyl group (182 $24.5 \mathrm{mg}$ ) and control group (208 $18.7 \mathrm{mg}$ ) (table 3). Kazemeini et al. ${ }^{6}$ in his study on the effect of local injections of bupivacaine plus ketamine, bupivacaine alone, and placebo on reducing postoperative anal fistulectomy pain showed that the mean overall dose of opiates required by patients who was treated with wound infiltration with bupivacaine and ketamine was significantly lower than control group. Normal defecation post-surgery depends on the extent of pain, duration of operation and also normal urination ${ }^{8}$. In our current study VAS score during first defaecation was lower in DM group than Fentanyl and control group (Table $4)$ and it was statistically significant $(p<0.05)$. There was no significant difference in defecation score between Fentanyl group and control group ( $>>0.05)$. Kang et al. ${ }^{13}$ 
showed that pain score during first dafaecation was lower in ropivacaine with dexmedetomidine group than ropivacaine alone group in wound infiltration technique. Biswas et al. ${ }^{16}$ in his study observed that dexmedetomidine when added to levobupivacaine in supraclavicular block, the systolic and diastolic blood pressure values of the Dexmedetomidine Group were lower in comparison with the Control Group and that the incidence of bradycardia was higher in the Dexmedetomidine Group. Also another study by Bicer et al. ${ }^{17}$ also demonstrated a significant decrease in post-block heart rate and mean arterial pressure values in both Bupivacaine Group and Bupivacaine with Dexmedetomidine Group in comparison with the preblock values. However, this effect lasted longer in the Bupivacaine with Dexmedetomidine Group. In our study, there were no statistically significant differences in MAP (mean arterial pressure), heart rate and respiratory rate among the three groups. The study by Aksu et al. ${ }^{18}$, addition of dexmedetomidine to the bupivacaine for TAP block and the study by Abdelnaim et al. ${ }^{11}$, addition of dexmedetomidine to the bupivacaine wound infiltration for herniorrhaphy surgeries showed that there was no statistically significant difference in the incidence of nausea and vomiting. Similar to them, in our current study, there was no significant difference in the incidence of nausea vomiting among the groups $(\mathrm{p}>0.05)$ (Table 5). Bielka et al. ${ }^{19}$ in his study on dexmedetomidine infusion as an analgesic adjuvant during laparoscopic cholecystectomy showed there was no inter-group difference in the incidence of postoperative sedation. However other studies by Xiao et al. ${ }^{20}$ and Manne et al. ${ }^{21}$ showed a higher incidence of sedation in the dexmedetomidine group. In our study, there was no statistically significant difference in sedation score between groups $(p>0.05)$ though DM group had higher median sedation scores than those of Fentanyl and control group in first 12 hours. None of them needed oxygen supplementation in their postoperative period. Within the DM group, Fissure in ano patients had a longer postoperative analgesia $1170 \quad 103.9$ min than other Haemorrhoidectomy patients $685.3 \quad 58.6$ and fistula in ano patients $700 \quad 117.9$ and the difference was statistically significant $(\mathrm{p}<0.01)$ (Table: 6 )

\section{CONCLUSION}

Dexmedetomidine added to bupivacaine in wound infiltration at the end of surgery in perianal surgeries significantly reduces postoperative pain, 24 hours analgesic consumption and the pain score during first defecation. Dexmedetomidine is superior additive than Fentanyl.

\section{REFERENCES}

1. Bharathi RS, Sharma V, Dabas AK, Chakladar A. Evidence based switch to perianal block for ano-rectal surgeries. Int $\mathrm{J}$ Surg. 2010; 8(1):29-31.

2. Sharma MK, Vadhera A, Dey M, Kurumapu G. Efficacy of perianal nerve blockfor day care ano-rectal procedures. 2018;7(1):182-5

3. Shim SM, Park JH, Hyun DM et al.. (2018) The effects of adjuvant intrathecal fentanyl on postoperative pain and rebound pain for anorectal surgery under saddle anesthesia. Korean J Anesthesiol 71(3):213-219

4. Honca M, Dereli N, Kose EA, Honca T, Kutuk S, Unal SS et al... Low-dose levobupivacaine plus fentanyl combination for spinal anesthesia in anorectal surgery. Rev Bras Anestesiol. 2015; 65: 461-465

5. Kim BG, Kang $\mathrm{H}$. The effect of preemptive perianal ropivacaine and ropivacaine with dexmedetomidine on pain after hemorrhoidectomy: a prospective, randomized, doubleblind, placebo-controlled study. Indian $J$ Surg. 2014;76(1):49 - 55. doi:10.1007/s12262-012-0622-5

6. Kazemeini A, Rahimi M, Fazeli MS, Adeleh MS, Ghaderi H, Fani K, Forozeshfard M, Matin M. The effect of local injections of bupivacaine plus ketamine, bupivacaine alone, and placebo on reducing postoperative anal fistula pain: A randomized clinical trial. Scientific World Journal 2014; 2014:1-6.

7. Vinson-Bonnet B, Coltat JC, Fingerhut A, Bonnet F. Local infiltration with ropivacaine improves immediate postoperative pain control after hemorrhoidal surgery. Dis Colon Rectum 2002;45:104-108.

8. Gudaityte J, Marchertiene I, Pavalkis D. Anesthesia for ambulatory anorectal surgery. Medicina 2004;40:101-11

9. Yu et al...: Transversus abdominis-plane block versus local anesthetic wound infiltration in lower abdominal surgery: a systematic review and meta-analysis of randomized controlled trials. BMC Anesthesiology 2014 14:121.

10. Bhardwaj S, Devgan S, Sood D, Katyal S.Comparison of local wound infiltration with ropivacaine alone or ropivacaine plus dexmedetomidine for postoperative pain relief after lower segment cesarean section. Anesth Essays Res 2017;11:940-5.

11. Abdelnaim, H.E., Mohamed, N.N., Saleh, A.H. et al... Comparison between bupivacaine-dexmedetomidine mixture and bupivacaine-magnesium mixture when used for wound infiltration before skin incision in surgeries for hernia repair regarding their intraoperative and postoperative analgesic effects. Ain-Shams J Anesthesiol 2018: 10, 10.

12. Kadyan N, Khatri ML. Comparison of dexmedetomidine and fentanyl as adjuvant for wound infiltration to bupivacaine for postoperative pain relief after abdominal hysterectomy. J Dent Med Sci 2017;16:11-4.

13. Kang H, Kim BG. Intravenous lidocaine for effective pain relief after inguinal herniorrhaphy: A prospective, randomized, double-blind, placebo-controlled study. J Int Med Res 2011;39:435-45.

14. Chander R, Liddle D, Kaur B, Varghese M. Wound infiltration with plain bupivacaine as compared with bupivacaine fentanyl mixture for postoperative pain relief after abdominal surgery. Anesth Essays Res 2011;5:142-6.

15. Selvaraj V, Kamaraj R. Effect of dexmedetomidine as an adjuvant to $0.25 \%$ bupivacaine for local infiltration of port 
site in laparoscopic cholecystectomy in terms of quality and duration of post-op analgesia. JARSS. 2019; 27(3): 210-216

16. Biswas S, Das RK, Mukherjee G, Ghose T. Dexmedetomidine an adjuvant to levobupivacaine in supraclavicular brachial plexus block: a randomized double blind prospective study. Ethiop J Health Sci. 2014;24(3):203 - 208.

17. Biçer C, Ünalan E N, Aksu R, Onal O, Guneş I. Addition of dexmedetomidine to bupivacaine in ultrasonography-guided paravertebral blockade potentiates postoperative pain relief among patients undergoing thoracotomy. Rev. Bras. Anestesiol. 2019 ; 69( 2 ): 144-151.

18. Aksu R, Patmano G, Biçer C, et al... Efficiency of bupivacaine and association with dexmedetomidine in transversus abdominis plane block ultrasound guided in postoperative pain of abdominal surgery. Rev Bras Anestesiol. 2018;68:49-56.

19. Bielka K, Kuchyn L, Babych V, Martycshenko $\mathrm{K}$, Innozemtsev O. Dexmedetomidine infusion as an analgesic adjuvant during laparoscopic c holecystectomy: a randomized controlled study. BMC Anesthesiology 2018; 18: 1-6.

20. Xiao C, Lu B, Yao J, sun J. Effect of dexmedetomidine in acute postoperative pain relief is independent of suppressing the hyperalgesia induced by remifentanil. Zhonghua Yi Xue Za Zhi. 2013; 93:44-7.

21. Manne GR, Upadhyay MR, Swadia V. Effects of low dose dexmedetomidine infusion on haemodynamic stress response, sedation and post-operative analgesia requirement in patients undergoing laparoscopic cholecystectomy. Indian J Anaesth. 2014; 58:726-31.

\begin{tabular}{|l|}
\hline Source of Support: None Declared \\
Conflict of Interest: None Declared
\end{tabular}

\section{Policy for Articles with Open Access:}

Authors who publish with MedPulse International Journal of Anesthesiology (Print ISSN:2579-0900) (Online ISSN: 2636-4654) agree to the following terms: Authors retain copyright and grant the journal right of first publication with the work simultaneously licensed under a Creative Commons Attribution License that allows others to share the work with an acknowledgement of the work's authorship and initial publication in this journal.

Authors are permitted and encouraged to post links to their work online (e.g., in institutional repositories or on their website) prior to and during the submission process, as it can lead to productive exchanges, as well as earlier and greater citation of published work. 